\title{
Mechanical Properties and Abrasive Wear of Different Weight Percentage of TiC Filled Basalt Fabric Reinforced Epoxy Composites
}

\author{
Anand Chelliah $*$ *(1) \\ ${ }^{a}$ Department of Mechanical Engineering K.Ramakrishnan College of Engineering -Trichy, India
}

Received: June 19, 2018; Revised: November 06, 2018; Accepted: November 23, 2018

\begin{abstract}
Fiber reinforced polymers are very rarely applied as wear-resistant materials because of the lack of good mechanical strength, which adversely affects the properties of the composites. To improve the mechanical and abrasive wear resistant of the composites, fillers are incorporated into the polymers. Hence in this work composites are produced by adding functional inorganic fillers such as Titanium Carbide (TiC) and basalt fabric as reinforcement. The composites have been fabricated by using vacuum assisted resin transfer moulding (VARTM). Abrasive tests were conducted using pin-on-disc instrument by varying abrasive distances at different loads of 5, 10 and $15 \mathrm{~N}$.After the incorporation of TiC filler in basalt fabric reinforced epoxy composite a significant reduction in weight loss were observed. Composites containing $2 \mathrm{wt} \%$ TiC exhibit the lowest weight loss among other $4 \mathrm{wt} \%$ and $6 \mathrm{wt} \% \mathrm{TiC}$ filled epoxy composites. The surface topography the composites were analyzed by using scanning electron micrographs (SEM).
\end{abstract}

Keywords: abrasive wear, basalt fiber, epoxy, TiC, SEM.

\section{Introduction}

Marine and mining industries extensively used polymer composites over other conventional metals, since it has high strength to weight ratio than metals. Polymer composites with higher stiffness and strength are obtained with fibres as reinforcement and resins as matrix. The environmental friendly composites are made by natural fibres which are become popular in the manufacturing of fiber reinforced polymers. Out of various existing natural fibres the basalt fiber, which is known as 21 st century material becomes a positive impact on the polymer based composites. It is being popular because of a naturally occurring volcanic material from the earth crust.Also basalt as a base composite can replace steel in light weight concrete, where $1 \mathrm{~kg}$ of basalt reinforces equals $9.6 \mathrm{~kg}$ of steel ${ }^{1-4}$. Recent years the technology development in composites tend to the production of basalt fiber as low cost compared to the production of other existing fibers ${ }^{5,6}$. TN Babu ${ }^{7}$ illustrated and reviewed the possibility of industrial applications of the basalt fibre reinforced composites. Incorporation of basalt fibre as reinforcing material to polyimide resin composites results in excellent wear properties over unreinforced one.The influence of the short basalt fiber content, the load, and sliding speed on the tribological behaviour of the polyimide composites were examined. Experimental results revealed that the low addition of basalt fiber improved the tribological behaviour of polyimide composites ${ }^{8}$. Recently Wang et.al ${ }^{9}$ developed a new resin system based on furan and epoxy that can be used for

*e-mail: mechanand2003@gmail.com basalt fibre. They concluded that basalt fibre-reinforced furan/ epoxy composites showed excellent mechanical properties.

Composites result from the addition of filler materials reduces the usage of matrix in the composites. The reason to incorporate filler into a polymer is to improve the tribological, mechanical and thermal properties as reported by Pihtili and Tosun ${ }^{10}$ and to reduce the cost of the final product as stated by Tayeb and Yousif ${ }^{11}$. Incorporation of lubricants and inorganic fillers in the polymer composites can improve the wear resistance significantly ${ }^{12,13}$.Sabeel et.al ${ }^{14}$ studied the effect of ceramic fillers on the wear behaviour of jute/epoxy composites. Among the various ceramic fillers, TiC provides more hardness to the matrix. In abrasive environment, hardness of the material plays a major role in improving the wear resistance of the composite. Investigation on tribological behaviour of natural fiber composites is very little which motivates to do research on these materials.Qi-huaWang et.al ${ }^{15}$ improved the wear resistance of basalt fabric composites by adding graphite and nano- $\mathrm{SiO}_{2}$. Matykiewicz et.al ${ }^{16}$ suggested that the addition of zeolite and silsesquioxane as fillers which improved the thermo-mechanical properties of basalt fibre reinforced epoxy composites. Khosravi and Farsani ${ }^{17}$ concluded that matrix reinforcing with surface-modified nano clay was found to significantly enhance the mechanical responses of basalt reinforced epoxy composite. For better mechanical properties the interface between fibre and matrix is also a major factor ${ }^{18}$. By incorporating suitable wear resistance filler materials, it can be expected that the wear properties of fiber composites may significantly improve. Several researchers studied the tribological properties of basalt fabric and pointed out that the friction and wear properties varied continuously with the different fillers for most polymers and the optimal properties 
were found at a certain filler weight ratio, although some data reported were contradicting. However, the wear behaviour of basalt fabric with TiC as filler is not studied so far. Hence this paper investigated the abrasive wear resistance of the TiC particles with different weight percentage in the basalt fabric reinforced epoxy composites.

\section{Materials and Methods}

\subsection{Materials}

The epoxy matrix investigated is a medium viscosity epoxy resin (LY556) with a density of $1.15-1.20 \mathrm{~g} / \mathrm{cm}^{3}$ and a room temperature curing hardener (HY 951) both supplied by Javanthee Enterprises (Huntsman distributor), Chennai, India. The resin is a clear liquid with 1000-1500 $\mathrm{mPas}$ viscosity at $25^{\circ} \mathrm{C}$, and a specific gravity of $1.17 \mathrm{~g} / \mathrm{cc}$. The hardener is a liquid with $40-60 \mathrm{mPas}$ viscosity and a specific gravity of $0.94 \mathrm{~g} / \mathrm{cc}$. The Titanium carbide powder with average particle size $15 \mu \mathrm{m}$ obtained from M/s. Ultimate Enterprises Pvt., Chennai. The basalt plain weave fabrics of 150 gsm were obtained from Asamer basaltic fibers-Austria is used as reinforcement. The image of basalt fabric is shown in Figure 1.The SEM image of the TiC filler particle size distribution is shown in Figure 2.

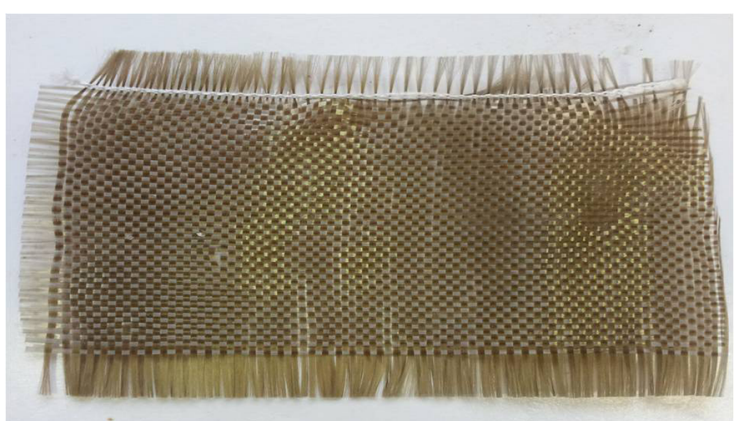

Figure 1. Image of woven basalt fabric.

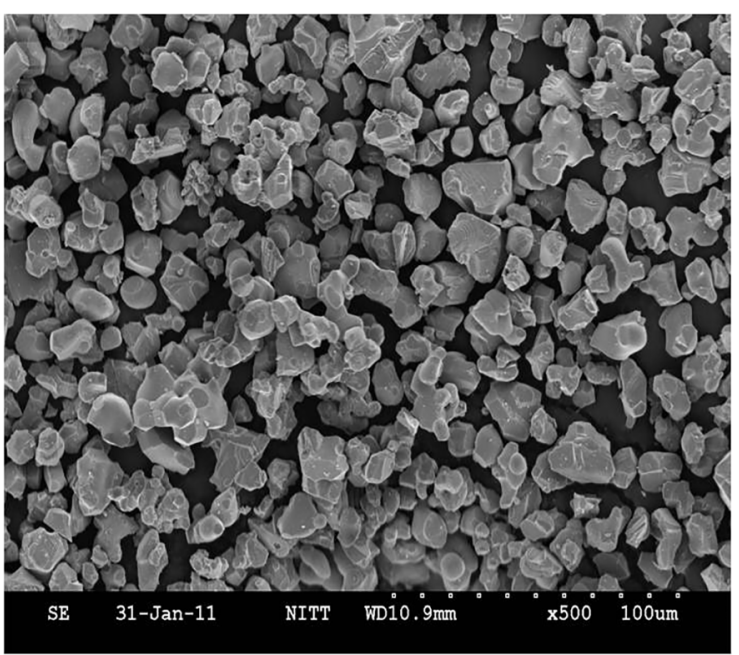

Figure 2. SEM image of TiC filler.

\subsection{Fabrication of composites}

Figure 3 illustrates the schematic of Vacuum Assisted Resin Transfer Moulding (VARTM) process. In this process first the mould was cleaned and the releasing agent was applied on the mould surface. Next the layers of dry basalt fabrics were laid up on the mould surface. Then peel ply material was applied to cover the fiber perform. The flow distribution medium layer was applied on the top of the peel ply. The resin injection port was placed on one end of the flow distribution medium layer. The vacuum bag was carefully laid up the on the assembly. Next the injection port was closed and the vacuum port was opened for to apply the vacuum inside the bagged preform assembly. Before the resin was introduced, the trapped air inside the mold was removed by turning the pump on. The resin was allowed to fill the resin reservoir by keeping the vacuum port on. The injection port was closed until the resin cured into the solid part. During this time the vacuum will keep the preform assembly tightly and maintain the uniform compressive pressure on the preform to create a composite part with a uniform thickness. Once the resin fully cured into the solid phase, vacuum ports turned off and the basalt resin reinforced composite parts was removed from the mold. In this process, the pressure difference between the vacuum pressure and the environmental pressure used to compress the preform against the mold and draw the resin into the preform.

Figure 4 shows a schematic of 'vacuum bagged' VARTM process. For manufacturing the composites the ratio of epoxy resin to hardener was 100:38 on a weight basis. Using mechanical stirrer the epoxy resin and filler was mixed with a speed of $250 \mathrm{rpm}$ for 10 minutes.

In this process, a single sided rigid mold is used which is sealed with a flexible bag. It is done by drawing a vacuum to remove the air from the mold and placed on the tool surface. The resin injection is continued until the resin is seen exiting from the vent ports. At this point, vent ports are closed and the resin is allowed to cure. The cure may be initiated by heating the mold and/or by addition of inhibitors to the resin system initially. After the part is sufficiently hardened, the mold is opened.

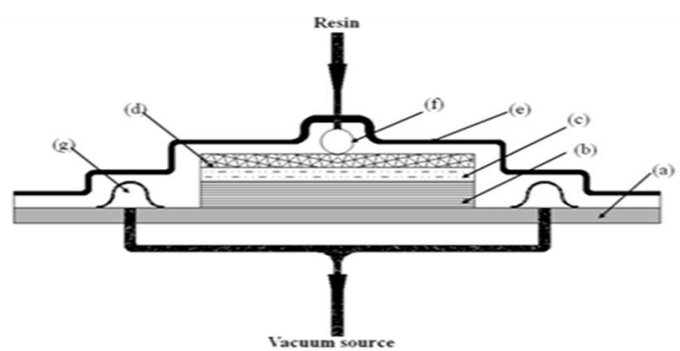

Figure 3. Schematic of VARTM setup a) granite moulding sand b) basalt fabric c) peel ply material d) distribution medium e) vacuum bag f) resin inlet $g$ ) vacuum outlet process of filled and unfilled epoxy composites. 


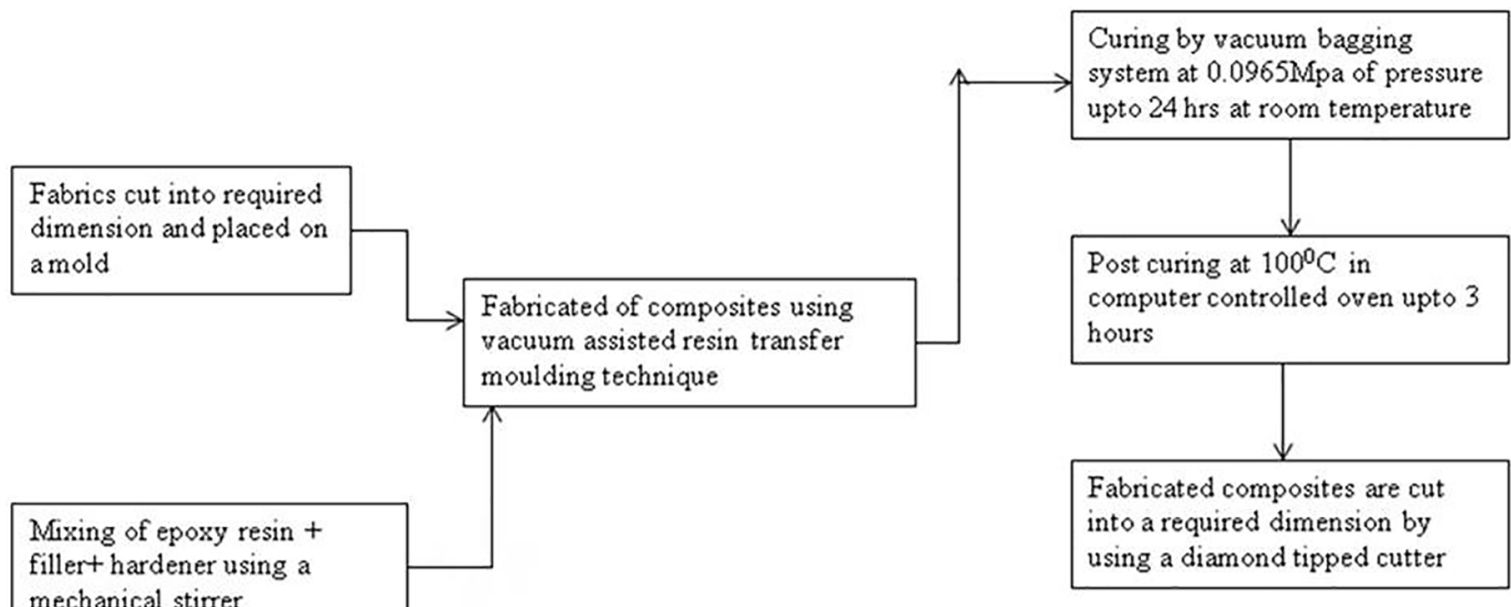

Figure 4. Fabrication process of filled and unfilled epoxy composites.

\subsection{Experimental setup}

\subsubsection{Pin-on-disc Wear Test-rig}

A pin-on-disc instrument (as per ASTM G-99 standard) is used for two-body abrasive wear tests. The surface of the $\left(5 \times 5 \times 3 \mathrm{~mm}^{3}\right)$ composite specimen was glued to a pin of $8 \mathrm{~mm}$ diameter and $27 \mathrm{~mm}$ length and the other side is in contact with water proof $\mathrm{SiC}$ abrasive paper, which is fixed on a rotating disc. The specimens were placed with the plain fabric oriented in parallel to the sliding plane and with the warp parallel to the abrading direction. To make uniform contact with the counter surface; the specimens were polished against a 600 grade $\mathrm{SiC}$ paper. The embedded hard $\mathrm{SiC}$ particles abraded the test samples. The disc and the specimen surfaces were cleaned with a soft paper soaked in acetone and thoroughly dried before the test. The pin assembly was initially weighed to an accuracy of $0.1 \mathrm{mg}$ in an electronic balance. The difference between the initial and final weights is the measure of weight loss.

The details of the two body abrasion wear test conditions are given in Table 1

\section{Results and Discussions}

\subsection{Mechanical properties}

In this study, the reinforcement of $\mathrm{TiC}$ particulate in basalt fiber reinforced epoxy resin has shown encouraging

Table 1. Details of the two body abrasion wear test conditions

\begin{tabular}{lc}
\hline Test conditions & Parameters \\
\hline Dimension of the specimen $\left(\mathrm{mm}^{3}\right)$ & $5 \times 5 \times 3$ \\
Applied load $(\mathrm{N})$ & 5,10 and 15 \\
Angular speed (rpm) & 200 \\
Sliding diameter $(\mathrm{mm})$ & 40 \\
Abrading Distance $(\mathrm{m})$ & $25,50,75$ and 100 \\
\hline
\end{tabular}

results in terms of mechanical properties. From the Table 2 the Mechanical properties of unfilled and TiC filled B-E composites are obtained. The tensile strength values are $215.23 \pm 6 \mathrm{MPa}, 187.05 \pm 4 \mathrm{MPa}$ and $161.28 \pm 6 \mathrm{MPa}$ respectively whereas the tensile strength of epoxy with woven basalt fiber is about $146.45 \pm 4 \mathrm{MPa}$.As per the ASTM standard for consistent of result tested minimum three to four test has to be conducted for each tensile test specimen. In all the tests conducted we get low standard deviation. A low standard deviation indicates that the specimen tested different times has nearly the same values for all the properties and that the tested values has consistent results. The impact properties of composite materials are directly related to its overall toughness. The presence of TiC improved the impact strength of TiC filled B-E composites (Table 2).

It is interesting to note that the addition of small amount of TiC significantly improves the tensile strength of basalt epoxy composites. Further addition ( $4 \& 6$ wt. \%) however, lowers the strength value drastically. There can be two reasons for this decline in the strength properties of $6 \mathrm{wt}$. $\%$ TiC filled B-E composites compared to the $2 \mathrm{wt} . \% \mathrm{TiC}$ filled composites. They are

1. The chemical reaction at the interface between the filler and the matrix may be too weak to transfer the tensile stress.

2. The corner points of the irregular shape of the particulate result in stress concentration in the epoxy matrix.

The tensile modulus is increased with 2 wt. \% of filler content in the composite; increase in tensile modulus after 2 wt. $\%$ of the filler is not substantial. The increase in tensile modulus for $2 \mathrm{wt} . \%$ is due to the constraint imposed on the matrix deformation and the interface strength does not have a significant influence on the composite modulus. Similar observation has been reported by Junlin Chen et al. ${ }^{19}$

The hardness values of the composites with filler content of 2 wt. $\%, 4$ wt. $\%$ and 6 wt. $\%$ are recorded as $44.5 \mathrm{Hv}$, 
Table 2. Mechanical properties of unfilled and TiC filled B-E composites

\begin{tabular}{|c|c|c|c|c|c|c|c|}
\hline S.No & Composite & $\begin{array}{c}\text { Tensile } \\
\text { strength }(\mathrm{MPa})\end{array}$ & $\begin{array}{l}\text { Tensile } \\
\text { modulus } \\
(\mathrm{GPa})\end{array}$ & $\begin{array}{l}\text { Compressive } \\
\text { strength } \\
(\mathrm{MPa})\end{array}$ & $\begin{array}{l}\text { Impact } \\
\text { Energy } \\
(J)\end{array}$ & $\begin{array}{l}\text { Impact } \\
\text { strength } \\
(\mathrm{J} / \mathrm{mm})\end{array}$ & $\begin{array}{l}\text { Hardness } \\
\text { (Hv) }\end{array}$ \\
\hline 1 & $\begin{array}{l}\text { Basalt Fabric } \\
\text { reinforced epoxy } \\
(B-E)\end{array}$ & $146.45 \pm 4$ & $29.08 \pm 0.3$ & $166.18 \pm 7$ & $3.3 \pm 3$ & $1.03 \pm 0.003$ & $43.75 \pm 2$ \\
\hline 2 & $\begin{array}{c}2 \mathrm{wt} . \% \mathrm{TiC}+\mathrm{B}-\mathrm{E} \\
(\mathrm{B}-\mathrm{E}+2)\end{array}$ & $215.23 \pm 6$ & $30.01 \pm 0.3$ & $182.17 \pm 7$ & $5.4 \pm 3$ & $1.68 \pm 0.003$ & $44.5 \pm 2$ \\
\hline 3 & $\begin{array}{c}\text { 4wt. \% } \mathrm{TiC}+\mathrm{B}-\mathrm{E} \\
(\mathrm{B}-\mathrm{E}+4)\end{array}$ & $187.05 \pm 4$ & $23.58 \pm 0.3$ & $138.61 \pm 7$ & $6.5 \pm 3$ & $2.03 \pm 0.003$ & $46 \pm 2$ \\
\hline 4 & $\begin{array}{c}\text { 6wt. \% } \% \text { TiC +B-E } \\
(\mathrm{B}-\mathrm{E}+6)\end{array}$ & $161.28 \pm 6$ & $24.48 \pm 0.3$ & $122.41 \pm 7$ & $4.67 \pm 3$ & $1.45 \pm 0.003$ & $48.75 \pm 2$ \\
\hline
\end{tabular}

$46 \mathrm{Hv}$ and $48.75 \mathrm{Hv}$ respectively. The hardness of unfilled composite is found to be $43.75 \mathrm{Hv}$. It is observed that the hardness is improved, by the incorporation of $\mathrm{TiC}$ in the composite as shown in (Table 2).

The reduction in tensile strength and the improvement in hardness with the incorporation of filler can be explained as follows: under the action of a tensile force the filler matrix interface is vulnerable to de-bonding. This may lead to a crack in the composite and it weakens the interfacial bond strength.

In the case of hardness test, a compression or pressing stress is in action. So the matrix phase and the solid filler phase would be pressed together and they touch each other tighter. Thus, the interface can transfer pressure more effectively, although the interface bond may be poor. This results in enhancement of hardness of TiC filled B-E composites.

Under compressive loading, the fillers apparently add to the load bearing capability of a composite, rather than act as stress raisers as in the case in tensile loading. This is due to compressive stresses tends to close cracks and flaws that are perpendicular to the applied stress, contrary to the crack opening mechanism occurring in a tensile loading situation as indicated by Friedrich et al. ${ }^{20}$

It is well known that failure occurs in the composite immediately adjacent to the contact area between the filler and the resin. This is caused primarily by compressive stresses acting on the surface. Hence, B-E+6 composite have a lower compressive strength than that of $\mathrm{B}-\mathrm{E}+4$ and B-E +2 composite (Table 2).

The presence of agglomeration of $\mathrm{TiC}$ in the $\mathrm{B}-\mathrm{E}+4$ and $\mathrm{B}-\mathrm{E}+6$ composites deteriorates their mechanical properties. Agglomerations may easily happen to smaller particles at higher filler contents due to the reduced interparticle distance as specified by Hagstrand and Bonjour ${ }^{21}$.

\subsection{Weight loss}

The plots of weight loss as a function of abrading distances of B-E,B-E+2,B-E+4 \& B-E+6 composites (abraded against 400 grit water proof $\mathrm{SiC}$ paper) at three different loads of 5 , 10 and $15 \mathrm{~N}$ are shown in Figure 5 (a-c), respectively. The reported data consist of the mean values of three or more tests together with the standard deviations represented by the vertical bars. From Figure 5 (a)-(c), it is observed that the weight loss of the composites increases with increase in abrading distance and applied load. A lowest weight loss of $0.019 \mathrm{~g}$ was observed for $\mathrm{B}-\mathrm{E}+2$ composite at $25 \mathrm{~m}$ abrading distance at $5 \mathrm{~N}$ load. Highest weight loss of $0.078 \mathrm{~g}$ was observed for unfilled B-E composite at a $100 \mathrm{~m}$ abrading distance with $15 \mathrm{~N}$ load. In addition, higher wear losses were noticed for all composites tested at $15 \mathrm{~N}$ load.

\subsection{Morphology of worn out surface}

In abrasive wear situation when grits start abrading the surface of the fibers, they came to contact in both the longitudinal and transverse direction. Fibers in transverse direction offer more resistance to motion because grit tries to elongate and then cut the fiber.

The SEM features the worn surfaces of unfilled and TiC filled B-E composite at a load of $5 \mathrm{~N} \& 15 \mathrm{~N}$ on 400 grit abrasive $\mathrm{SiC}$ paper and at abrading distances of $100 \mathrm{~m}$ are shown in Figure $6 \& 7$. The worn surface of unfilled B-E composite at $5 \mathrm{~N}, 100 \mathrm{~m}$ abrading distance is shown in Figure 6. SEM micrograph of figure 6(a)depicts more damage to the epoxy matrix and basalt fibers as compared with that of TiC filled B-E composites. Also micro-cracking, chip formation, exposure of fiber and fibre breakage was occurred in B-E composites.

TiC filled B-E composite shows more stable wear performance than unfilled B-E composite. Figure 6(a-d) shows the worn surfaces of filled and unfilled TiC composite tested under a constant load at $5 \mathrm{~N}$ and fixed distance at 25 $\mathrm{m}$.Figure 6 (b-d) represents that, the matrix is damaged by ploughing and cutting action by the presence of $\mathrm{SiC}$ particles. Also the worn surfaces were much smoother and the basalt fiber detachment was remarkably limited with the addition of $\mathrm{TiC}$ particles. The presence of $\mathrm{TiC}$ in resin protects the fiber from further damage to the applied load. At lower abrading distances (Figure $6 \mathrm{~b}$ ) the existence of TiC particles in the epoxy matrix on the surface of the composite is inferred to act as an effective barrier to prevent the damage and exposure of the fiber. The extent of damage to the matrix and fiber 

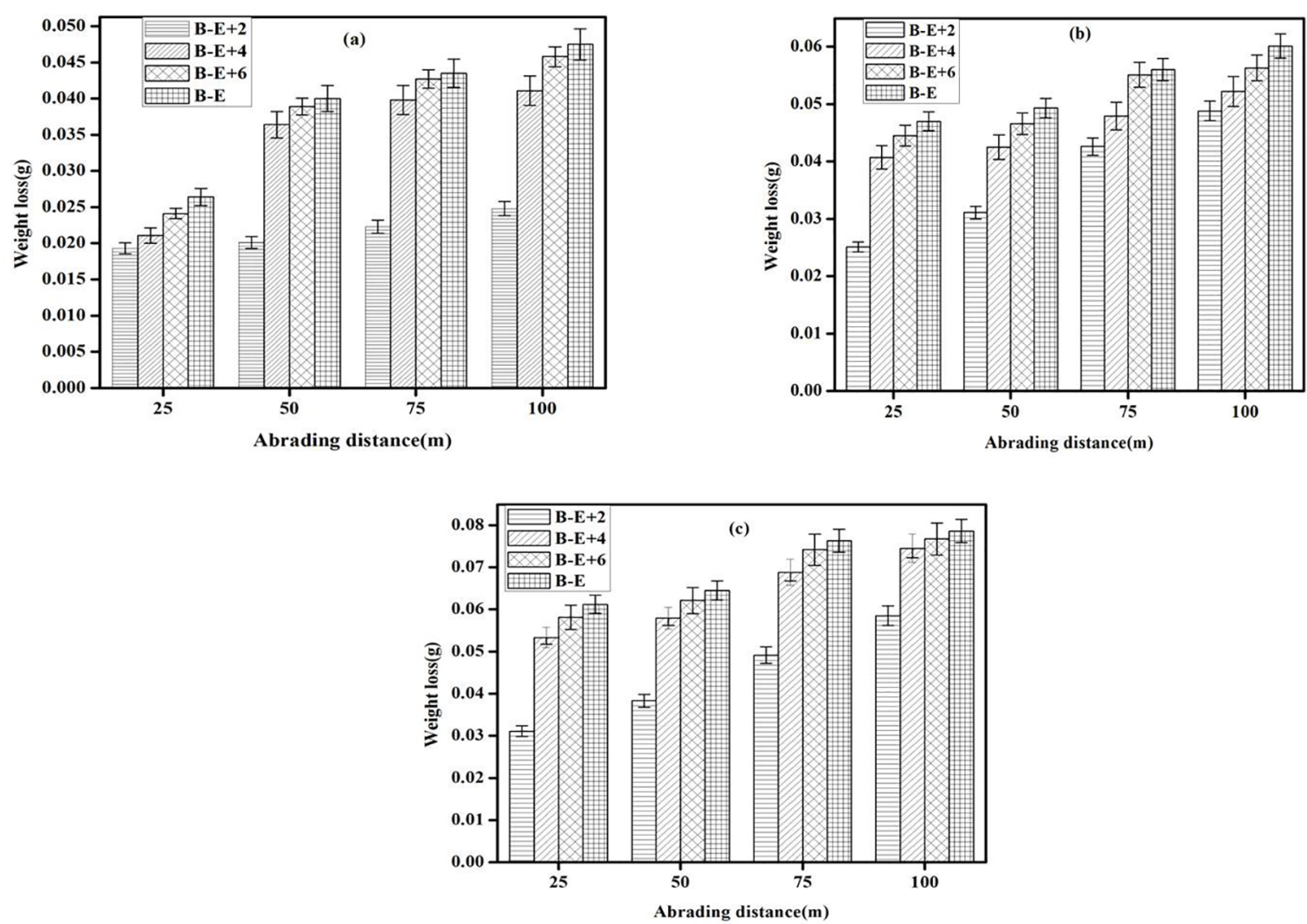

Figure 5. (a) The plot of weight loss as a function of abrading distances of B-E, B-E+2, B-E+4 \& B-E+6 composites at a) $5 \mathrm{~N}$ b) $10 \mathrm{~N}$ c) $15 \mathrm{~N}$.

is less in $\mathrm{B}-\mathrm{E}+2$ composite as compared to unfilled B-E composite under the same test conditions.

For B-E +2 composites the load sharing between fibers are significant resulting in better bonding with epoxy matrix. This result is in agreement with the SEM micrograph (Figure $6 \mathrm{~b})$. But from the worn surfaces of B-E+4 and B-E+6, severe damage to the matrix, less fiber breakage and some fibre pull-out from the surface is noticed. The sub surface damage zones of the B-E +6 were deeper than that of B-E +4 and B-E +2 composites. Fibre fracture occurred in the contact region as well as in the sub-surface region (Figure $6 \mathrm{a} \& \mathrm{~d}$ ). Fibre removal from the contact region was enhanced by the ploughing and cutting of the matrix between the exposed fibres. De-lamination cracking takes place in the sub surface up to a depth of about two to three fibre layers.

SEM image Figure (7 a) of B-E composite at $15 \mathrm{~N}, 100 \mathrm{~m}$ abrading distance shows the fiber cutting and void formation as chips come out of the matrix perpendicular to the wear direction. At high load, B-E composite exhibits severe matrix failure because, at the initial stage of abrasion, an abrasive particle is in contact with less hard matrix and the rate of material removal is very high. Fiber breakage is minimum at $5 \mathrm{~N}$, while at $15 \mathrm{~N}$, it has increased significantly. The furrows made by grits are marked on the surfaces showing micro-ploughing and micro-cutting actions. The wear behaviour is varying with the content of TiC at $15 \mathrm{~N}, 100$ $\mathrm{m}$ abrading distance. When the load increases, the amount of fiber damage also increases, that supports the high wear resistance of composites at high load.SEM images $7 \mathrm{c}$ and $7 \mathrm{~d}$ indicate that the damage to fiber, matrix cracking, broken and crushed fibers and fiber pull-out occurred at B-E+4 composites. B-E+6 (figure 7d) composites indicated more fiber pulverization, more fiber breakage and fiber-matrix de-bonding compared to B-E+2, B-E+4 composites. Evidence of large amount of matrix debris was observed for all composites. Similar results were obtained by Chand and $\mathrm{Neogi}^{22}$. Wear tests at higher abrading distance for $\mathrm{B}-\mathrm{E}, \mathrm{B}-\mathrm{E}+4$ and $\mathrm{B}-\mathrm{E}+6$ composites indicated that fiber fracture and pulverization were pre-dominantly seen and this resulted in severe damage to fiber and matrix. But for $\mathrm{B}-\mathrm{E}+2$ composite, at higher abrading distance (Figure $7 \mathrm{~b}$ ) a good interfacial bonding between filler and matrix exists that resists the damage of fiber and protects it in position. For $\mathrm{B}-\mathrm{E}+2$ composite uniform dispersion of TiC powder in the matrix resists the penetration of abrasive particles which was enveloped by fiber.

At lower loads, wear loss is less because only resin surface was removed. By increasing the load from $5 \mathrm{~N}$ to $10 \mathrm{~N}$, wearing out and micro fracture of a certain amount of epoxy matrix and fibers was observed. This leads to an increase in the overall wear loss. On further increasing the load to 15 $\mathrm{N}$ the fibers start fracturing and spread on the counter face. 

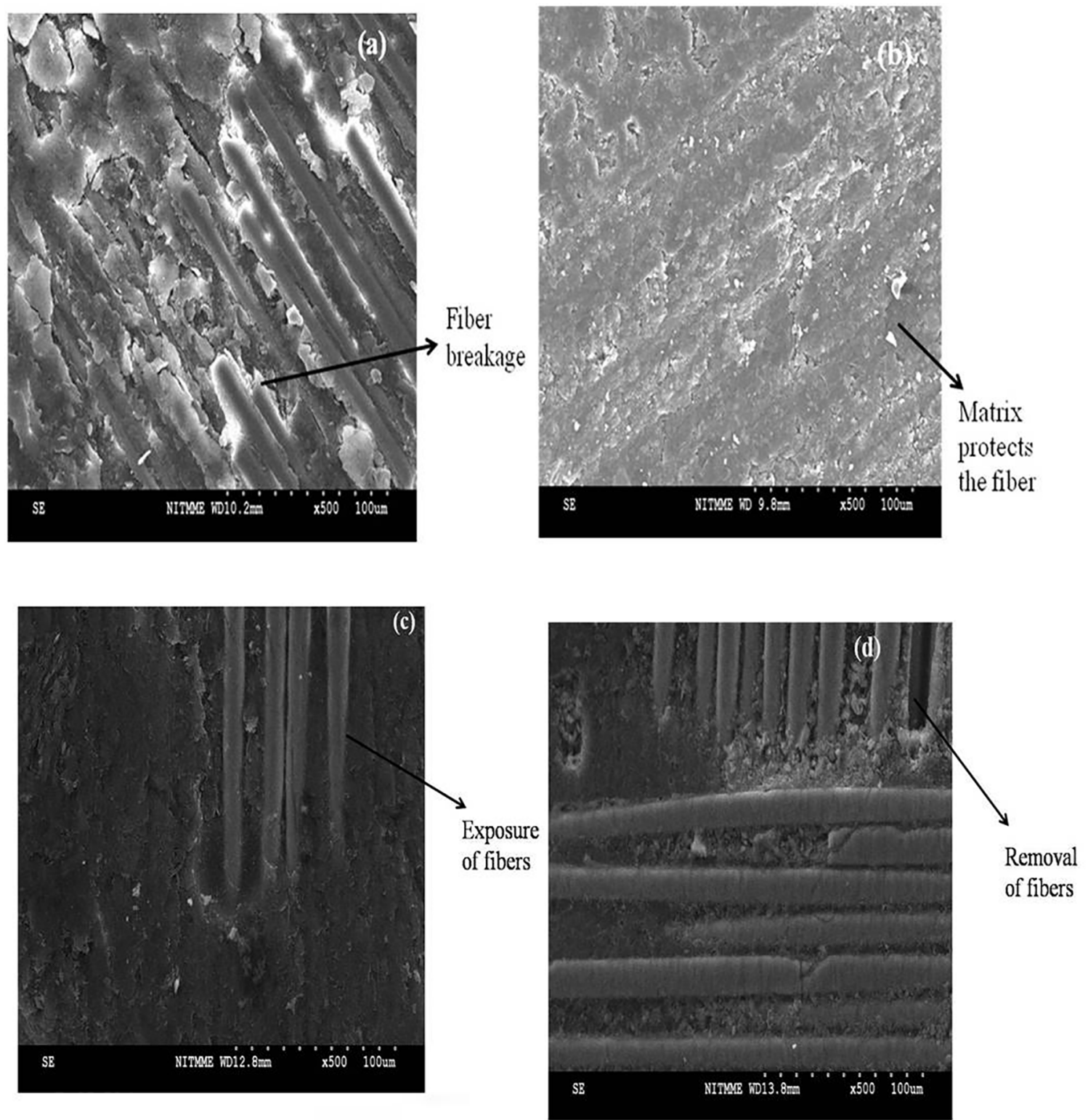

Figure 6. SEM picture of the worn surface of a) B-E b) B-E +2 composite at a load of $5 \mathrm{~N}, 100 \mathrm{~m}$ abrading distance. SEM picture of the worn surface of c) B-E+4 d) B-E +6 composite at a load of $5 \mathrm{~N}, 100 \mathrm{~m}$ abrading distance.

The depth and width of furrows due to micro-ploughing is higher at higher load. The shearing action of grits cuts the fibers and the cut pieces are lifted away and rolled out of the contact zone in the subsequent actions. Bundles of broken fibers have been removed from the matrix. The further crushing action of these fibers increases the wear damage on the surface of specimens. The excessive de-bonding between fibers and matrix is observed as a result of severe shearing action of the grit.At all load B-E+2composite exhibits lower weight loss and hence good wear resistance at all applied loads. Fiber damage is maximum in Figure $7 \mathrm{c}$ and $7 \mathrm{~d}$ which confirms its poor performance.
At a higher abrading distance for $\mathrm{B}-\mathrm{E}+4$ and $\mathrm{B}-\mathrm{E}+6$ composites, there is an evidence of exposure of longitudinal fibers in the direction perpendicular to the abrasion with no damage. A big cavity, left after the removal of fibre piece accounts for highest wear of $\mathrm{B}-\mathrm{E}+4$ and $\mathrm{B}-\mathrm{E}+6$ composites. The reasons for the decrease in the wear resistance can be attributed to the poor adhesion or bonding at the interface between the matrix and the filler. Similar observations were reported by Gourav et. $\mathrm{al}^{23}$. Under low weight fraction, the dispersion of the particles in the matrix was good enough to resist the wear of the composites. Hence particles of low weight fraction seemed to be more effective in improving the wear resistance of the filler filled composites. 

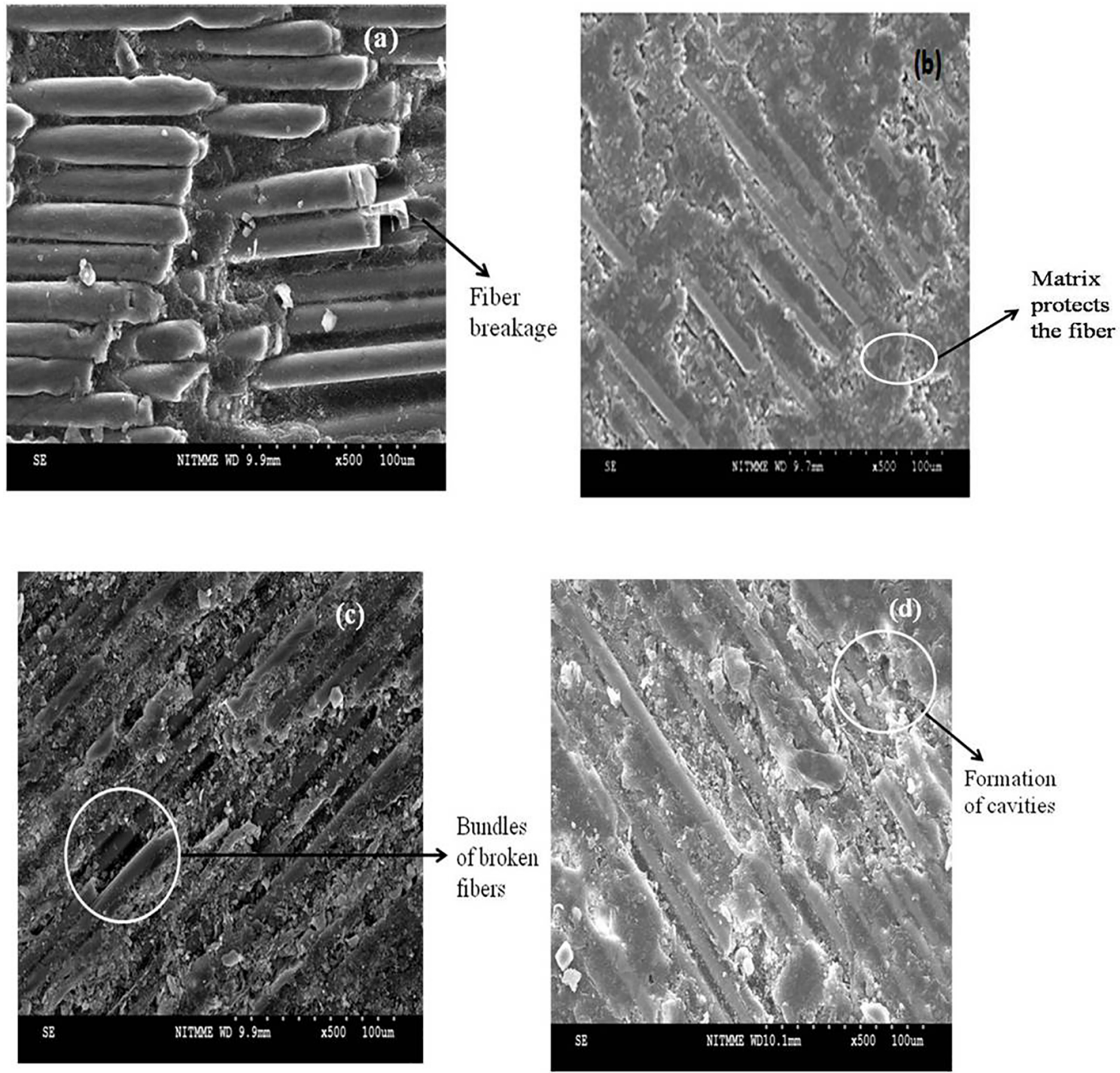

Figure 7. SEM picture of the worn surface of a) B-E b) B-E+2 c) B-E+4 d) B-E+6 composite at a load of $15 \mathrm{~N}, 100 \mathrm{~m}$ abrading distance.

\section{Conclusions}

The current study revealed the potential of applying basalt fibres in wear resistance applications through the filler filled epoxy composites. The incorporation of $2-6 \mathrm{wt} \% \mathrm{TiC}$ particles to form filled composites indicates that $2 \mathrm{wt} \% \mathrm{TiC}$ yields good mechanical properties over other filled and unfilled composites. The weight loss was found more in B-E composites with increase in abrading distance as compared to TiC filled B-E Composites. The enhancement on the wear resistance and fracture toughness after incorporation of TiC filler in B-E composite was generally associated with less matrix and fiber damage and/or removal. TiC filled B-E composite exhibits more stable wear performance under all test conditions, due to the presence of $\mathrm{TiC}$ particles on the counter surface, which act as a transfer layer and effective barrier to prevent large-scale fragmentation. The abrasion wear resistance of filled composites was found to increase with the addition $2 \mathrm{wt} \% \mathrm{TiC}$ particle content. However, increasing particle weight content beyond $4 \%$ decreased the wear resistance of the composites.SEM studies of worn surfaces suggested the mechanism of wear as micro- cracking, chip formation, exposure of fibers, fiber cracking/breakage and displacement of broken fibers. The benefit of adding $\mathrm{TiC}$ in B-E composites is to obtain low wear rate and high hardness which in turn resists the abrasive wear. Hence it is suggested to use the above composites in high abrasive wear resistance applications.

\section{References}

1. Deshmukh G. Basalt - The Technical Fibre. Man Made Textiles in India. 2007;50(7):258-261.

2. Saravanan D. Spinning the Rocks - Basalt Fibres. Journal of the Institution of Engineers India. 2006;86:39-45. 
3. Artemenko SE, Kadykova YA. Polymer composite materials based on carbon, basalt, and glass fibres. Fibre Chemistry. 2008;40(1):37-39.

4. Pakharenko VV, Yanchar I, Pakharenko VA, Efanova VV. Polymer composite materials with fibrous and disperse basalt fillers. Fibre Chemistry. 2008;40(3):246-252.

5. Dorigato A, Pegoretti A. Fatigue resistance of basalt fibers reinforced laminates. Journal of Composite Materials. 2012;46(15):17731785 .

6. Carmisciano S, De Rosa IM, Sarasini F, Tamburrano A, Valente M. Basalt woven fiber reinforced vinylester composites: Flexural and electrical properties. Materials \& Design. 2011;32(1):337342.

7. Narendiranath Babu T, Ramesh D, Rama Prabha D, Lavanya T. Wear Behaviour of Hybrid Composite of Basalt Fiber with Titanium Oxide, Barium Sulphate and Silicon Carbide. International Journal of ChemTech Research. 2015;8(4):2053-2062.

8. Zhang X, Pei X, Wang Q. Friction and wear properties of polyimide matrix composites reinforced with short basalt fibers. Journal of Applied Polymer Science. 2009;111(6):2980-2985.

9. Wang Z, Cao N, He J, Du R, Liu Y, Zhao G. Mechanical and anticorrosion properties of furan/epoxy-based basalt fiberreinforced composites. Journal of Applied Polymer Science. 2017;134:44799.

10. Pihtili H, Tosun N. Investigation of the wear behaviour of a glass fibre-reinforced composite and plain polyester resin. Composite Science and Technology. 2002;62(3):367-370.

11. Yousif BF, El-Tayeb NSM. Wear characteristics of thermoset composite under high stress three-body abrasive. Tribology International. 2010;43(12):2365-2371.

12. Agarwal G, Patnaik A, Sharma RK. Thermo-mechanical properties of silicon carbide filled chopped glass fiber reinforced epoxy composites. International Journal of Advanced Structural Engineering. 2013;5:21.

13. Raghavendra G, Ojha S, Acharya SK, Pal SK. A comparative analysis of woven jute/glass hybrid polymer composite with and without reinforcing of fly ash particles. Polymer Composites. 2016;17(3):658-665.
14. Ahmed KS, Khalid SS, Mallinatha V, Amith Kumar SJ. Dry sliding wear behaviour of $\mathrm{SiC} / \mathrm{Al}_{2} \mathrm{O}_{3}$ filled jute/epoxy composites. Materials \& Design (1980-2015). 2012;36:306-315.

15. Wang QH, Zhang XR, Pei XQ. Study on the friction and wear behavior of basalt fabric composites filled with graphite and nano-SiO ${ }_{2}$. Materials \& Design. 2010;31(3):1403-1409.

16. Matykiewicz D, Lewandowski K, Dudziec B. Evaluation of thermomechanical properties of epoxy-basalt fibre composites modified with zeolite and silsesquioxane. Composite Interfaces. 2017;24(5):489-498.

17. Khosravi H, Eslami-Farsani R. Enhanced mechanical properties of unidirectional basalt fiber/epoxy composites using silanemodified Na+-montmorillonite nanoclay. Polymer Testing. 2016;55:135-142.

18. Lee JJ, Nam I, Kim H. Thermal stability and physical properties of epoxy composite reinforced with silane treated basalt fiber. Fibers and Polymers. 2017;18(1):140-147.

19. Chen J, Wang K, Zhao Y. Enhanced interfacial interactions of carbon fiber reinforced PEEK composites by regulating PEI and graphene oxide complex sizing at the interface. Composites Science and Technology. 2017;154:175-186.

20. Friedrich K, Evstatiev M, Fakirov S, Evstatiev O, Ishii M, Harrass M. Microfibrillar reinforced composites from PET/ PP blends: processing, morphology and mechanical properties. Composites Science and Technology. 2005;65(1):107-116.

21. Hagstrand PO, Bonjour F, Månson JAE. The influence of void content on the structural flexural performance of unidirectional glass fibre reinforced polypropylene composites. Composites Part A: Applied Science and Manufacturing. 2005;36(5):705714.

22. Dwivedi UK, Chand N. Influence of MA-g-PP on abrasive wear behaviour of chopped sisal fibre reinforced polypropylene composites. Journal of Materials Processing Technology. 2009;209(12-13):5371-5375.

23. Agarwal G, Patnaik A, Sharma RK. Comparative investigations on three-body abrasive wear behaviour of long and short glass fiber-reinforced epoxy composites. Advanced Composite Materials. 2014;23(4):293-317. 